\title{
Economic analysis of ecosystem based adaptation and engineering options: A case study from Udayapur, Nepal
}

\author{
Dinesh Chandra Devkota ${ }^{1 *}$, Kamal Thapa ${ }^{2}$ and Bhaskar Karki ${ }^{3}$ \\ ${ }^{1}$ Central Department of Environmental Science, Tribhuvan University, Kathmandu \\ ${ }^{2}$ Centre for Green Economy Development-Nepal, Kathmandu \\ ${ }^{3}$ International Centre for Integrated Mountain Development, Kathamndu
}

\begin{abstract}
Ecosystem services are vital to our well-being as they directly or indirectly support our survival and quality of life. But, the growing impact of climate change diminishes the benefit from ecosystem services. Therefore, identifying possible applicable adaptation options are inevitable to reduce the effect of climate change. The present research is based on a case study of Ksedi River watershed, Ajgada Village in Udaypur district of Nepal. The study demonstrates the comparison between different options to deal with flood and make a sound decision, based on economic rationale for long-term benefits. The present study compares ecosystem based adaptation options with engineering options using cost benefit analysis in order to protect village from flooding. Through stakeholder and expert consultations, ecosystem based adaptation options and economic options that are feasible in the village and catchment to mitigate the floods were listed. Economic analysis of these options and the different combinations were done using cost benefit analysis. Analysis was carried out for each of the different combination of options. Focus on ecosystem based adaptation options provide high benefit to cost return in terms of avoided damages and considering engineering options efficient in flood and erosion control in initial stage in spite of its high cost. The study suggests that reforestation in upland forest areas; plantation along riverbed and management of rangeland should be prioritized. Similarly, preparation of flood model, flood height damage curve and flood vulnerable maps specific to the site will help decision makers to implement site specific adaptation options.
\end{abstract}

Key words: Climate change, economic analysis, ecosystem based adaptation, engineering options

\section{Introduction}

The services provided by environment and ecosystems are essential for the survival of living being. It provides benefits that enhance economic performance, offer new opportunities, and improve living standards and quality of life (Secretariat of the Convention on Biological Diversity, 2010). Despite these advances, human beings are using the natural resources in unsustainable manner and climate change also adding pressure on it. The growing anthropogenic emission of carbon dioxide, a potent green house gas, into atmosphere has now taken as unequivocal cause of global warming and thereby causing change in climate. Though, Nepal emits negligible share of green house gas (MoPE, 2016), its adverse impacts are disproportionally felt in Nepal due to its mountainous topography. The low level of adaptation capacity, low economic strength, inadequate infrastructure, low level of social development, lack of institutional capacity, and higher dependency on the natural resource makes the countr y vulnerable to change in climatic system including variability and extreme events. The adverse effects of climate variability and extreme events put additional stress on overall development of Nepal (MoE, 2010). The $\mathrm{k}$ ey water related disasters are flood, drought, erosion and landslide that may occur with greater frequency or intensity in the future.

The present research is focused on a case study of Ksedi River watershed, Ajgada village in Udaypur district in which the comparison of different adaptation options with economic analysis to deal with flood are discussed for long-ter $m$ benefits. This research specifically compares ecosystem based adaptation options with engineering options using cost benefit analysis to protect village from flooding.

Recurrent flood and landslide are major impacts that make Nepal extremely vulnerable. According to WECS (2011), the devastating flood and landslide are triggered by different mechanisms such as continuous rainfall and cloudburst, GLOFs and landslide dam outburst in Nepal. 
Implementation of immediate adaptations and mitigation measures is inevitable to minimize the potential damages caused by these extreme events. In response to these underlined impacts, various adaptation options (both non-structural and structural measures) are still under exploration and implementation. However, selection of cost effective adaptation options through systematic economic analysis is still limited. Therefore, this study intended to carryout economic analysis and recommend cost effective ecosystem based adaptations as well as engineering options.

The study was carried out with the following objectives;

- To document possible ecosystem based adaptations and engineering options

- Economic analysis of individual ecosystem based adaptations and engineering options

- To recommend appropriate and cost effective ecosystem based adaptations and engineering options to be implemented.
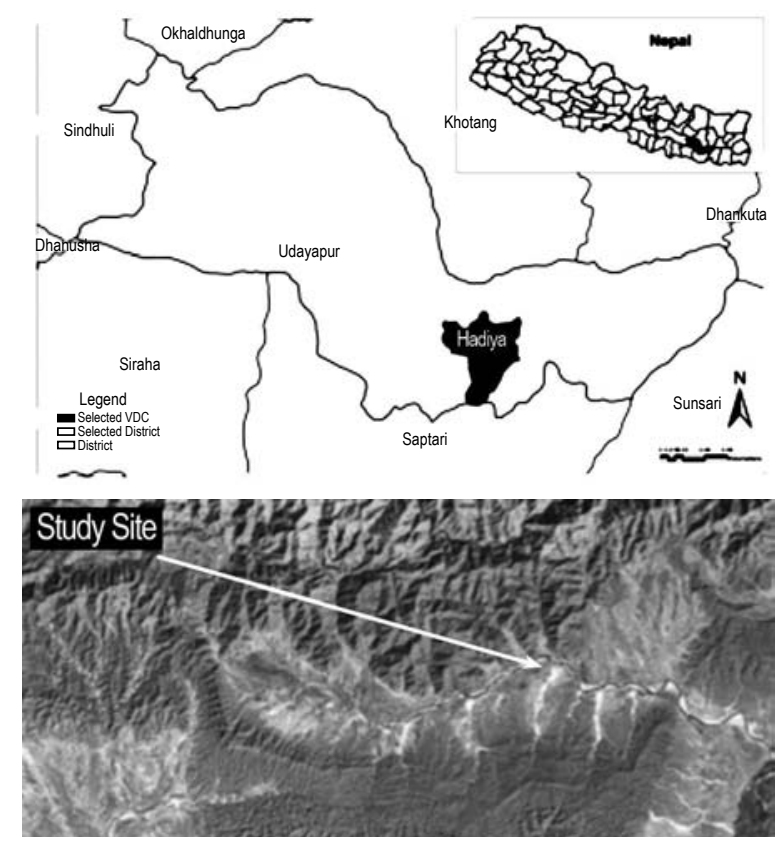

Fig. 1 Map showing Ajgada Village of Hadiya VDC, Udaypur

\section{Materials and methods}

A highly flood prone Ksedi River watershed of Udayapur district was selected for the study. Ecosystem based adaptation options and economic options which are feasible in the village and catchment area to mitigate the impact of floods were recorded through stakeholder and expert consultations. Primary data was generated through the consultation with 300 respondents. Economic analyses of each option with different combinations were calculated. The economic analysis included the cost of implementation and the benefit retained from implementation of the options without damage. The adaptation options and its economic analysis to protect from flooding in Ajgada V illage in Udayapur district involved following steps:
1. Least cost and benefit cost analysis were per formed for the selected adaptation options in the Ksedi River watershed. The cost of implementation of adaptation options were calculated using standard cost of labor and materials published by District Development Committee, Udayapur. Through focus group discussion and k ey informant survey of the Ksedi River watershed and Udayapur district, the cost of avoided damages of a flood event was calculated through benefit transfer method. The economic approach, allowed the ranking of options and scenarios to ensure the most economically optimum choice, as a guide for decision making to policy development. Leastcost analysis (US EPA, 2014) provides the specific sum of costs of each of the chosen adaptation options over a period of years.

$$
C=\sum_{1}^{T, N} c_{t, n}(1+i)^{-t}
$$

2. The cost of inaction, that is, the cost of not pursuing any of the adaptation options was calculated. These costs include health, business, public property and household costs, resulting from flood, some of which can be avoided by adaptation actions. To estimate the cost of flood damages, flood damage information from Udayapur district and Ajgada village was used.

3. Three scenarios ranging from ecosystem based adaptation options to engineering options for flood protection was developed with defined actions in each scenario.

4. A cost benefit analysis of three scenarios was performed. The benefit-cost ratio, which is the ratio of the present value of benefits to the present value of costs, was calculated. A sensitivity analysis was performed to examine the effects at different time horizons (10 and 20 years) and discount rates (3\%, $7 \%$ and $10 \%$ ). Benefit-cost analysis (BCA) is a method used to evaluate the economic desirability of a proposed action that has certain benefits and certain costs associated with it. It is a technique used to analyze policy alter natives, and is commonly used by the United States Environmental Protection Agency (US EPA) and many other organizations to analyze the economic feasibility of alter native projects or proposed investments. A net present value (NPV) BCA (Eq. 2) was used to analyze the economic consequences of ecosystem-based adaptation and engineering options for flood related adaptations in Udayapur district.

$$
N P V=\sum_{1}^{T, N} b_{t, n}(1+i)^{-t}-\sum_{1}^{T, N} c_{t, n}(1+i)^{-t}
$$

The annualized NPV (ANPV) (Eq. 3) is the average yearly net return over the lifetime of the suite of adaptation options, that is, the annualized cash flow.

$$
A N P V=\left[\frac{i}{(1+i)^{-T}}\right] N P V
$$

\section{综TU-CDES}


The benefit-cost ratio (BCR) (Eq. 4) is the ratio of the present value of discounted benefits to the present value of the discounted costs for the action. This outcome of the analysis can provide decision-makers with an intuitive answer regarding the desirability of the project. If the ratio is greater than one, then the project is desirable, and the ratio itself gives the benefits per rupees spend on the project.

$$
B C R=\sum_{1}^{T, N} b_{t, n}(1+i)^{-t} / \sum_{1}^{T, N} c_{t, n}(1+i)^{-t}
$$

\section{Results and discussion} Ecosystem based adaptations

Ecosystem-based adaptation (EbA) integrates the use of biodiversity and ecosystem services into an overall strategy to help people adapt to the adverse impacts of flood. It includes the sustainable management, conservation and restoration of ecosystems to provide services that help people adapt to both cur rent climate variability and climate change. Ecosystem based adaptation involves a wide range of ecosystem management activities to increase resilience and reduce the vulnerability of people and the environment to climate change (Colls et al., 2009).

\section{Economic analysis I - least cost analysis}

Different adaptation options were determined during a site visit to Ksedi River watershed in 2014. The locations were identified for implementation of adaptation options (EbAs and EOs). During interaction meeting with community and district level stakeholders, district rate of labor and materials in Udayapur district, the general cost of adaptation options were estimated (Table 1). The costs of implementing the adaptation options in Ksedi River watershed to control flood were collated and summed over a 20 years and 40 years time period at a discount rate of $3 \%$ (Table 1).

Table 1 Cost of each option implemented in Ksedi River watershed, calculated over 20 years and 40 years at a 3\% discount rate.

\begin{tabular}{lcc}
\hline Adaptation Options & \multicolumn{2}{c}{ Cost (10000 NPR) } \\
\cline { 2 - 3 } & 20 years & 40 years \\
\hline General Plantation & 355.0 & 551.6 \\
Bamboo Wattle & 268.1 & 416.6 \\
Broom grass (Amriso) Plantation & 8.2 & 12.7 \\
Natural wetland & 19.3 & 30.0 \\
Nursery & 119.0 & 184.9 \\
Bamboo Plantation & 15.3 & 23.8 \\
Fire Management & 55.0 & 85.5 \\
livestock Management & 14.9 & 23.1 \\
Monitoring and Support & 44.6 & 69.3 \\
Site Clearance & 9.4 & 14.6 \\
Excavation & 283.9 & 441.1 \\
Boulder Filling & 3331.5 & 5176.1 \\
Gabion Boxes & 2847.9 & 4424.7 \\
Geo-textile & 216.0 & 335.6 \\
Soil embankment & 1105.6 & 1717.8 \\
Artificial Wetland & 215.7 & 335.2 \\
\hline
\end{tabular}

Field obser vation in Ksedi River watershed suggests that the construction of gabion wall to protect Ajgada village is not sustainable for the river originating from Churia range, because the gabion wall are submerged due to high sedimentation and debris flow in the river. The effectiveness of adaptation options in affected area is not sustainable. It recommends that the adaptation options should be implemented in entire watershed to prevent debris flow and its impact. This analysis present the cost of selected adaptation options without its effectiveness. There are nine ecosystem based adaptations and seven engineering options. These options are not assumed on the basis of effectiveness, but only analyzed and compared on the basis of cost of implementation. This information will provide clear economic insight to design and make decision while implementing adaptation options in flood vulnerable/prone areas.

Fig. 2 shows the costs over 20 and 40 years and ranks the selected adaptation options from lowest to highest cost. The low cost adaptation options include: broom grass (Amriso) plantation, site clearance, livestock management, bamboo plantation, natural wetland, monitoring and support and fire management. The medium cost options include: nurser y establishment, artificial wetland, geo-textile, bamboo wattle, excavation and general plantation. The most expensive are soil embankment, gabion boxes and boulder filling (Fig. 2). Engineering options using gabion boxes, boulder filling, and soil embankment are most expensive due to high labor and material cost to constr uct the structures like spur, revetment and check dam.

Ecosystem based adaptations are cheap but take longer time for its effectiveness against flood and erosion. General plantation is in medium cost because this watershed needs intense plantation due to rapid deforestation as well as landslide and gully formation in upstream. Awareness and capacity building of local community also plays important role in flood control. Livestock management, fire management and support to local community can reduce the use of forest resources in unsustainable manner.

Constructions of natural and artificial wetland are essential in this watershed for conservation of water and protection the wildlife. Natural wetland holds the large amount of water during flood and artificial wetland ensures the water availability throughout the year for irrigation and recharging ground water.

Effectiveness of adaptation options vary regarding intensity and time period of rain. For example; embankment in the river gives instant result in protection of village due to flooding, but fire management helps in controlling flood indirectly by preser ving vegetation.

Further research on effectiveness of the adaptation options is essential for decision mak ers to implement the approaches. 


\section{Total Cost (100000 NPR)}

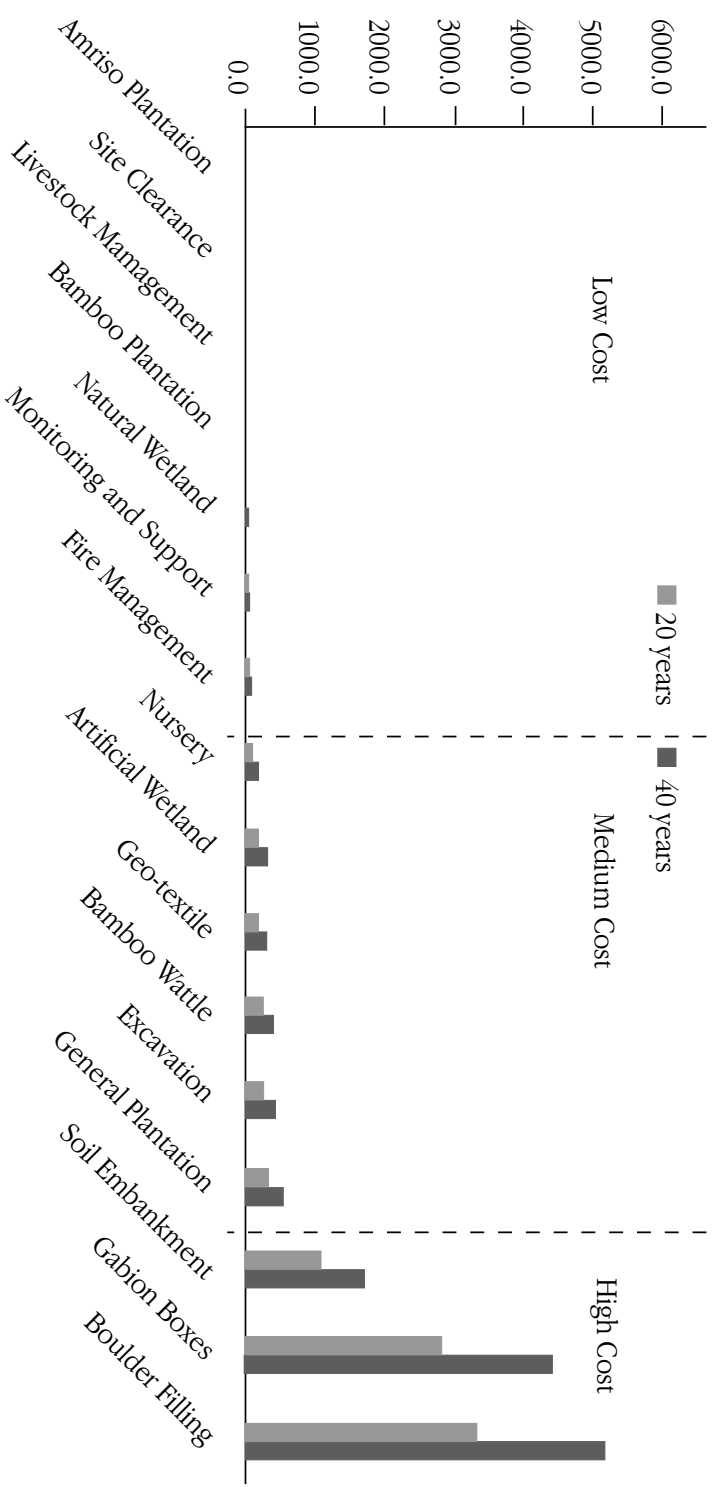

Fig. 2 Adaptation Options

Effectiveness of proposed adaptation options with cost effective adaptation options will provide optimum result for implementation to reduce flood risk at a minimum cost.

\section{Economic analysis II - benefit cost analysis}

The avoided damages due to flood are calculated and adjusted over different time periods and various discount rates. In sensitivity analysis, the calculations were on $100 \%$ of the total damage estimated and that was decreased to $10 \%$. The damage cost in Ksedi River watershed was based on infor mation given by community, district level stakeholders and key informants. For this analysis, the benefit-cost ratio for mulation equation 2 was used with 100\%, 50\%, 25\% and 10\% of the avoided damages as a potential benefit of implementing the selected adaptation options.
Table 2 Proportion of avoided damages for Ksedi River watershed (over 20 years at $3 \%$ discount rate)

\begin{tabular}{lcccc}
\hline Adaptation options & \multicolumn{5}{c}{ Assumed \% damage avoided } \\
\cline { 2 - 5 } & $\mathbf{1 0 0 \%}$ & $\mathbf{5 0 \%}$ & $\mathbf{2 5 \%}$ & $\mathbf{1 0 \%}$ \\
\hline Engineering options & 87 & 43 & 22 & 9 \\
Site clearance & 3 & 1 & 0.7 & 0.3 \\
Excavation & 0.3 & 0.1 & 0.06 & 0.02 \\
Boulder filling & 0.3 & 0.14 & 0.07 & 0.03 \\
Gabion boxes & 4 & 2 & 1 & 0.4 \\
Geo textile & 1 & 0.4 & 0.2 & 0.1 \\
Soil embankment & 4 & 2 & 1 & 0.4 \\
Artificial wetland & & & & \\
Ecosystem based adaptation & & 1 & 0.6 & 0.2 \\
Plantation & 2 & 2 & 1 & 0.3 \\
Bamboo wattle & 3 & 25 & 10 \\
Broom grass (Amriso) plantation & 99 & 50 & 25 & 4 \\
N. wetland & 42 & 21 & 11 & 4 \\
Nursery & 7 & 3 & 2 & 1 \\
Bamboo plantation & 53 & 27 & 13 & 5 \\
Fire management & 15 & 7 & 4 & 1.5 \\
Livestock management & 55 & 27 & 14 & 5 \\
Support & 18 & 9 & 5 & 2 \\
\hline
\end{tabular}

Benefit cost ratio will be high with higher benefit (in this case avoided damages were considered as benefit). The least expensive adaptations options will have high benefit cost ratio . In Ksedi River watershed, broom grass plantation, livestock management, bamboo plantation and site clearance have high benefit cost ratio, whereas boulder filling, gabion boxes and soil embankment have low benefit cost ratio. Although, the general plantation per square meter is affordable adaptation option, re-plantation along river and deforested areas with labor and maintenance cost will increase the overall cost.

Benefit should be high for a project to be desirable so as to benefit cost ratio. In this study, the ratios of EbA options are greater than one and have higher ratios and the ratios of most of EOs are also greater than one, but the ratios are very low compared to EbAs. However, only implementing higher benefit cost ratio options will not be sufficient to control flood and sedimentation. Both EbAs and EOs are equally important for sustainable flood control. According to research site analysis, it was found that the feasible adaptation may vary according to the different area. F or Ksedi River watershed, scenario analysis was used to examine the desirability of EbA, EO and Hybrid measures (combining EbAs and EOs) would be appropriate. The Hybrid measures were used in catchment area and village protection scenarios.

\section{Scenarios}

We may have a choice of constructing engineering structures or ecosystem based approaches or engineering str uctures with ecosystem based approaches for controlling flood. In engineering options, the strength of a structure declines over time and needs replacement after certain time period, whereas vegetation takes

\section{墖 TU-CDES}


a few years to reach maximum strength and last for a long time. As the relative strength of engineering str ucture decreases, the relative strength of bio-structure increases (Fig. 3). Thus, in the long run, function of the engineering structure is handed over to the ecosystem.

EbAs or EOs alone may not achieve all the functions for flood control management in cost effective manner . Therefore, combinations of both EbAs and EOs are required to reduce the impacts of flood. Vegetation also has the engineering functions which help to reduce erosion and controls flood (Fig. 4, Photo 1).

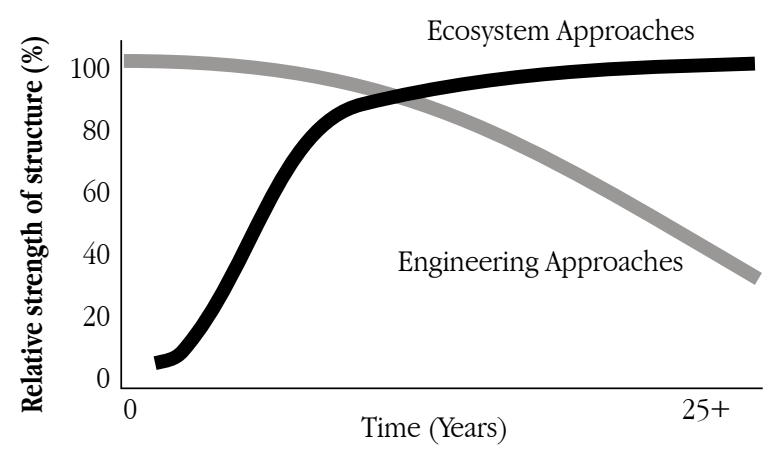

Fig. 3 Life span of engineering approaches and ecosystem approaches

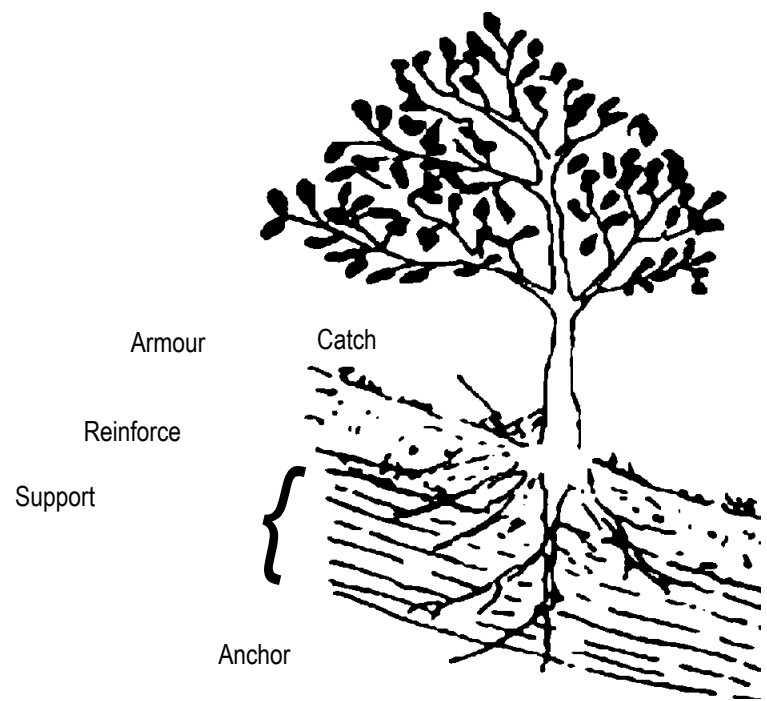

Fig. 4 Engineering function of vegetation

Economic analysis III - integrating scenarios into benefit cost analysis and including avoided damages

The scenario analysis was per formed to determine the benefit cost implications of the adaptation measures. The cost of scenarios was calculated as described in Economic Analysis II. The avoided damages were set at the $50 \%$ level and the sensitivity analysis was performed with various discount rates, time horizons and percentage of estimated damages avoided.

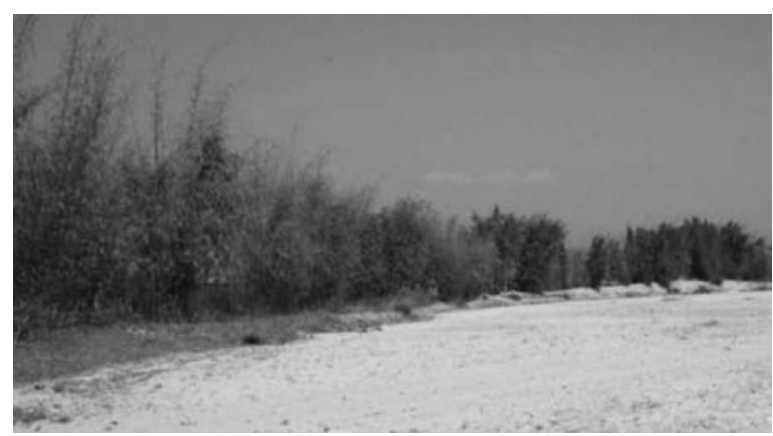

Photo 1 Bamboo wattle to stabilize slope and erosion control

The Table 3 shows the sums of avoided damages (at 50\%), EbA cost, EO cost, VP (village protection) cost and WP (watershed protection) cost. In EbA, the ecosystem measures were included for actions in entire watershed, whereas the engineering measures were included in EO. In VP and WP, ecosystem measures and engineering measures were included.

Table 3 Calculation of discounted cost and benefit for each scenario, calculated at 3\% discount rate and 20 and 40 years

\begin{tabular}{lcccc}
\hline \multicolumn{2}{l}{ Scenarios } & \multicolumn{2}{c}{ 20 years } & \multicolumn{2}{c}{ 40 years } \\
\hline \multicolumn{2}{c}{ Avoided damages } & Cost & Avoided damages & Cost \\
\hline EbA & $40,782,878.0$ & $44,979,133.2$ & $63,363,368.7$ & $69,882,988.75$ \\
\cline { 2 - 5 } EO & $40,782,878.0$ & $400,507,102.6$ & $63,363,368.7$ & $622,258,174.7$ \\
VP & $40,782,878.0$ & $255,054,679.0$ & $63,363,368.7$ & $396,272,270.8$ \\
CP & $40,782,878.0$ & $190,431,560.6$ & $63,363,368.7$ & $295,868,898.5$ \\
\hline
\end{tabular}

The Table 4 shows the economic analysis of each four scenarios included the net present value (NPV), annualized net present value (ANPV) and the benefit cost ratio

Table 4 Results of economic analysis for four scenarios, over 20 years at 3\% discount rate using Avoided damages benefits, shading shows conservatively estimated proportion of avoided damage for each scenario

\begin{tabular}{|c|c|c|c|c|c|}
\hline \multirow[b]{2}{*}{ Scenario } & \multirow[b]{2}{*}{ NPV } & \multirow[b]{2}{*}{ ANPV } & \multicolumn{2}{|c|}{ Assumed damage } & $\overline{\text { avoidance (\%) }}$ \\
\hline & & & $50 \%$ & $25 \%$ & $10 \%$ \\
\hline EbA & 8392510.5 & 564108.5 & 0.91 & 0.45 & 0.18 \\
\hline $\mathrm{EO}$ & 719448449.3 & 48358236.6 & 0.10 & 0.05 & 0.02 \\
\hline VP & 428543602.1 & 28804861.5 & 0.16 & 0.08 & 0.03 \\
\hline $\mathrm{CP}$ & 299297365.2 & 20117484.2 & 0.21 & 0.11 & 0.04 \\
\hline
\end{tabular}

The NPV and ANPV for all the scenarios are negative (T able 5). This indicates that the scenarios are not feasible to implement the mentioned adaptation options in the study area. The watershed has total 92 households and the cultivation and settlement area covers $0.27 \mathrm{sq}$. $\mathrm{km}$ of the total area $(5.9 \mathrm{sq} . \mathrm{km}$.) of watershed. The loss and damage in monetary term was calculated as US $\$ 56$, 861 in a flood event. The adaptation measures should be implemented in entire watershed to control flood which increase cost. The engineering measures to protect the village are essential and huge amount of money should be invested which increase the adaptation cost. The benefit cost ratio of all the scenarios are 
less than one in all percentage of the avoided damages. This clarifies that the lower avoided damage translates into lower benefit.

\section{Economic analysis part IV - benefit cost analysis including avoided damages and estimates of ecosystem service valuation}

Ecosystem services are the benefits which are obtained from ecosystems. Therefore, the monetary value of ecosystem is included for the analysis. The benefits from the selected ecosystem, direct and indirect, are imperative for the economic analysis.

The community of Ajgada village is dependent on natural resources and most of them are dependent on agricultural and forest. The poor and marginalized people mostly rely on ecosystem services. They obtain timber, fire wood, fodder, grass and medicinal plants for their survival. This has exploited the resources and increased vulnerability to climate change impacts as well.

The Table 5 shows the final economic analysis where adaptation costs have been integrated with avoided damage and ecosystem service value. Due to lack of proper value of ecosystem services, only provisioning, recreational and regulating service values are included. The benefit cost ratio of EbA and WP scenarios have value greater than one and ratio of $\mathrm{EO}$ and $\mathrm{VP}$ is negative, as the engineering measures to implement in these scenarios are high and so as the cost. The NPV and ANPV of EbA and WP are positive, and $\mathrm{EO}$ and VP are negative. The positive value shows that the present value of benefit of EbA and WP is greater than the present value of cost. The positive NPV suggest that the implementation of EbA and WP scenarios will improve the social welfare of Ksedi River watershed (Ajgada Village). The higher the benefit-cost ratio, the greater the welfare provided by that particular adaptation option. For example, assuming 50\% damage avoidance by all implemented scenarios, in the ecosystem-based adaptation scenario, the benefit-cost ratio was calculated to be 4.5. This indicates that for every one rupees invested into this scenario, the benefit is estimated at 4.5 rupees. From this analysis, it clarifies that only EbA scenario is desirable.

Table 5 Results of economic analysis for 20 years' time horizon and 3\% discount rate, including costs of implementation and benefits - avoided damages and ecosystem service benefits

\begin{tabular}{|c|c|c|c|c|c|}
\hline \multirow[b]{2}{*}{ Scenario } & \multirow[b]{2}{*}{ NPV } & \multirow[b]{2}{*}{ ANPV } & \multicolumn{3}{|c|}{ Assumed damage avoidance (\%) } \\
\hline & & & $50 \%$ & $25 \%$ & $10 \%$ \\
\hline $\mathrm{EbA}$ & 161164960.8 & 10832816.9 & 4.58 & 2.29 & 0.92 \\
\hline $\mathrm{EO}$ & 194363008.5 & 13064247.2 & 0.51 & 0.26 & 0.10 \\
\hline VP & 48910584.9 & 3287559.6 & 0.81 & 0.40 & 0.16 \\
\hline $\mathrm{CP}$ & 15712533.5 & 1056129.06 & 1.08 & 0.54 & 0.22 \\
\hline
\end{tabular}

The decision maker should have local knowledge and understand the risk in choosing the proper adaptation options for implementation. The economic analysis clarifies the topmost priority of scenarios to be implemented, but in case of Nepal with high risk of disaster and scattered settlement or less household with high vulnerability, the decision makers have to rely not only on economic analysis, but have to implement other scenarios for welfare of the community.

\section{Discussion \\ Least cost analysis}

Least cost analysis calculated for the overall cost of implementing each adaptation options for two-time horizon, 20 and 40 years with varying discount rate. Several adaptation options have the potential of long effective lifespan with appropriate maintenance. These actions range in effectiveness of damage avoidance as well as the expected time for initiation of provision of damage. Both the ecosystem-based adaptation options and the engineering options have quite a range of costs with the different solutions.

\section{Avoided damages}

Avoided damages are calculated by infor mation provided by inhabitants of Ajgada village and district level stak eholders of Udayapur that are incur red when no actions are tak en for its prevention. Hence, they are taken as estimated benefits for taking action.

The adaptation actions are preferable to no action, with suggested actions to reduce the damages and implications of flood events in Ksedi River watershed. The results showed that the low cost adaptation options are the one, which do not involve high installation costs. The relative effectiveness of options was not available in detail, and it is also recognized that both costs and effectiveness of these different options var y over time.

\section{Ecosystem service valuation}

The combination of spatial, primary data and economic analysis was used to determine the ecosystem service valuation of Ksedi River watershed. It was found that the main ecosystem of Ksedi River watershed is forest. Provisioning value of ecosystem service was estimated by FGD and KIS in Ajgada village applying benefit transfer method using data of Ilam, Nepal.

To provide clear picture on possible adaptation options to be implemented in Ksedi River watershed, the benefit and cost of four scenarios were compared with no action. The scenarios have different balance of EbA and EOs, where scenario 1 comprised of all EbA options, scenario 2 with all EOs and other two scenarios a combination of EbA and EOs focusing on catchment area and village.

\section{袮 TU-CDES}


Scenario 1: Ecosystem based adaptation options (EbA) This scenario focuses on maintaining natural resources from plantation, bamboo wattle, and natural wetland to preserve and re-establish the upland forest, rangeland and river beds. The capacity building of inhabitants includes livestock management training, fire management training and support to reduce the use of forest resources.

\section{Scenario 2: Engineering options (EO)}

This scenario focuses on engineering works to improve the infrastructue and implement new structures to limit the impacts of flood and erosion, and building barriers along river and adjacent areas like check dams, embankmnet, spur and revetment.

\section{Scenario 3: Catchment area (CA)- bybrid}

This scenario includes both EbAs and EOs, but focuses on the upland catchment area. It is considered as the source control.

Scenario 4: Village protection (VP) - bybrid

This scenario also includes both EbAs and EOs, but focuses on the low land, i.e. village area.

\section{Benefit cost analysis}

For the benefit cost analysis, we assume that engineering solutions provide $50 \%$ of the avoided damages; the hybrid solutions (CP and VP) provide $25 \%$ of the avoided damages; and ecosystembased adaptation provides $10 \%$ of the avoided damages. The economic analysis of four scenarios using estimated cost, avoided damages and estimate of ecosystem ser vice value is shown in Table 6.

Table 6 Benefit to cost ratio for each scenario of adaptation options with assumed percentage of damage avoidance

\begin{tabular}{lcc}
\hline Scenario & Benefit to cost ratio & Assumed damage avoidance \\
\hline EbA & 1.6 & $10-25 \%$ \\
Engineering Option & 0.4 & $25-50 \%$ \\
Catchment Protection & 0.5 & $25 \%$ \\
Village Protection & 0.4 & $25 \%$ \\
\hline
\end{tabular}

This study suggests that, EbA scenario have high outcome compared to other scenarios. When engineering structures are implemented, the cost will be high and so benefit to cost ratio become less than one. We can see that the EbA scenario will be the possible plan for Ksedi River watershed. However, EbA options only could not provide efficient results to prevent flood in initial stage, so decision makers should consider engineering options to achieve optimum result.

In this analysis, least cost approach was used to calulate the cost of each options and was ranked. Benefit cost analysis was performed for each adaptation options and for the four scenarios integrating different types of benefits to present whether the adaptation options should be implemented or not. In EbA and CP scenario, the benefit to cost ratio is greater than one and ANPV was positive, when ecosystem service values are integrated, other wise both analysis are negative. The results in which the ANPV or the benefit cost ratios were higher are actions or scenarios for which Ksedi River watershed would receive more benefit for each rupees spent.

The decision makers acquire the economic insight from this result, but for making a decision, they should focus on social issues, distribution of benefits, considering indigenous knowledge of local community. For decision makers, combining this learning and other related issues for planning and implementation will be fruitful.

\section{Conclusion}

Ksedi River watershed and entire Ajgada village is highly vulnerable to flood and sedimentation in agricultural lands. It has been found that intact forest and rangeland reduce flood and erosion, which decrease sedimentation in lowland areas and also provide forest resources and preserve water resources. Focus on ecosystem based adaptation options will provide high benefit to cost return in terms of avoided damages and considering engineering options that is efficient in flood and erosion control in initial stage rather than its high cost. During this study, it was found that there are data gaps regarding cost and effectiveness of different adaptation options, which limits the information for decision-making. Thus, the following recommendation are made.

- Priority should be given to reforestation in upland forest areas, plantation along river side and its management and management of rangeland as benefit to cost ratio is more than one for these actions.

- Engineering options should be tar geted to protect Ajgada village and crop land areas.

- Social issues should be integrated while planning to implement EbA and EOs.

- The adaptation options should be prioritized according to benefits received by the community.

- Flood model, flood height damage curve and flood vulnerable maps specific to the site should be developed which help decision makers to implement site specific adaptation options.

- This analysis should be improved using flood models, sitespecific flood vulnerable maps, watershed analysis, flood height, sedimentation and social issues.

\section{Acknowledgements}

The authors are thankful to ICIMOD for funding and to Integrated Development Society-Nepal (IDS Nepal) for entr usting overall study results. Similarly, the contribution from Prof. Dr. Govinda Nepal (Sr. Economist), V ijaya P oudel (EbA Expert), Sujit Karmacharya (Climate Change Officer), Er Rajesh Poudel (River Training/Bio Engineer), Suvash C Ghimire (Field Data Coordinator), enumerators and the local community are highly acknowledged. 


\section{Reference:}

Colls, A., N. Ash, \& N. Ikkala (2009). Ecosystem-based adaptation: A natural response to climate change. Gland, Switzerland: IUCN.

Andrade Pérez, A., Herrera Fernandez, B. \& CazzollaGatti, R. (eds.) (2010). Building resilience to climate change: Ecosystembased adaptation and lessons from the field. Gland, Switzerland: IUCN.

Bauer, K. (2013). Loss and damage from flooding in Udayapur district, Nepal: Loss and damage in vulnerable countries initiative, case study report. Bonn, United Nations University Institute for Environment and Human Security.

GoN (2011). National framework on local adaptation plans for action. Ministry of Environment, Government of Nepal, Kathmandu.

GoN (2013). District materials rate of Udayapur district, [Online], http://www.ddcudayapur.gov.np/ddcudaya/uploads/userfile s/files/dar_rate_nirman_70_71.pdf

IDS- Nepal, PAC, \& GCAP (2014). Economic impact assessment of climate change in key sectors in Nepal, IDS-Nepal, Kathmandu, Nepal.
MoPE (2016). Intended nationally determined contribution. (INDC), Ministry of Population and Environment, Government of Nepal, Kathmandu.

MoE (2010). Climate change vulnerability mapping for Nepal, Ministry of Environment, Government of Nepal, Kathmandu.

Pant, K. P., Rasul, G., Chettri, N., Rai, K. R. \& Sharma, E. (2012). Value of forest ecosystem services: A quantitative estimation from the Kangchenjunga landscape in eastern Nepal, ICIMOD Working Paper 2012/5. ICIMOD, Kathmandu.

US EPA (2014). Guidelines for preparing economic analyses. National Center for Environmental Economics Office of Policy. U.S. Environmental Protection Agency, USA.

Secretariat of the Convention on Biological Diversity (2010). Ecosystem goods and services in development planning: A good practice guide. Montreal.

WECS (2011). Water Resources of Nepal in the context of climate change. Ministry of Environment, Government of Nepal, Kathmandu. 